\title{
COMMUNICATION APPREHENSION AND INTERCULTURAL WILLINGNESS TO COMMUNICATE AMONG UNDERGRADUATES IN MALAYSIAN PUBLIC UNIVERSITIES
}

\author{
Pragash. $\mathbf{M}^{1}$, Sultana. $\mathrm{A}^{2}$, Khor. K. K ${ }^{3}$, Charles Ramendran ${ }^{4}$ \\ 1 Faculty of Arts and Social Science, Universiti Tunku Abdul Rahman (UTAR), Malaysia \\ Email: pragashm@utar.edu.my \\ 2 Faculty of Arts and Social Science, Universiti Tunku Abdul Rahman (UTAR), Malaysia \\ Email: sultana@utar.edu.my \\ 3 Faculty of Arts and Social Science, Universiti Tunku Abdul Rahman (UTAR), Malaysia \\ Email: khor@utar.edu.my \\ $4 \quad$ Faculty of Business and Finance, Universiti Tunku Abdul Rahman (UTAR), Malaysia \\ Email: charlesr@utar.edu.my
}

\section{Article Info:}

\section{Article history:}

Received date: 19.12 .2019

Revised date: 22.01 .2020

Accepted date: 29.01 .2020

Published date: 10.03 .2020

\section{To cite this document:}

Pragash, M., Sultana, A., Khor, K. K., \& Ramendran, C. (2020). Communication Apprehension and Intercultural Willingness to Communicate among Undergraduates in Malaysian Public Universities. International Journal of Law, Government and Communication, 5 (18), 01-11.

DOI: $10.35631 /$ IJLGC.518001.

\begin{abstract}
:
Willingness to interact with people from different cultures is the most fundamental factor for successful and effective intercultural communication, and also crucial in the simulation of desire for interaction in such context. However, high-level communication apprehension reduces the level of intercultural willingness to communicate, which eventually affects intercultural communication and vice versa. Meanwhile, some scholars argued that a moderate level of communication apprehension will increase intercultural willingness to communicate. Hence, this study started with the investigation of the level of both communication apprehension and intercultural willingness to communicate and ended with the investigation on the relationship between communication apprehension and intercultural willingness to communicate among multicultural undergraduates from five public universities in Malaysia. A total of 450 respondents were recruited to participate in this study. Neuliep and McCroskey's Intercultural Communication Apprehension scale and Kassing's Intercultural Willingness to Communicate scale were adopted and modified to assess respondents' communication apprehension and intercultural willingness to communicate, respectively. Data were coded, entered, and analysed using the IBM SPSS Statistics version 22. Our findings show that all respondents were having a moderate level of communication apprehension which eventually triggered a high level of intercultural willingness to communicate among these respondents. Pearson's correlation analysis revealed a significant positive correlation between the moderate level of communication apprehension and intercultural willingness to communicate, just like the results documented in the review of the literature. The implications of the findings are discussed at the end of this paper.
\end{abstract}




\section{Introduction}

Most people in the world are now connected with each other through different means of communication which has not only crossed borders but cultures in a more expanded level (Behbahani, 2013). Arnett (1986) professed that intercultural communication is not something modern; as long as individuals from distinctive societies have been experiencing one another, intercultural communication happens. Hence, the ability to communicate effectively in the global marketplace or even workplace is an increasingly essential competency, as well as an important area of exploration in academic research (Croucher, 2017).

Intercultural communication is important in establishing integration in a nation whereby the local and neighbourhood setting being the starting point of the integration processes (Behbahani, 2013). Past studies argued that the willingness to communicate interculturally often influenced by individual's communication apprehension (Seyitoglu, Guven, \& Kocabulut, 2015). However, there is no study ever investigated if multicultural Malaysian experience such communication apprehension towards intercultural communicate and its impact on intercultural willingness to communicate (IWTC).

Looking at the gap in the literature outlined above, the present study, therefore, is to examine the relationship between communication apprehension and IWTC among undergraduates in top five public universities in Malaysia.

As such, the research poses the following questions:

RQ1: What is the level of communication apprehension among undergraduates in Malaysian public universities?

RQ2: What is the level of intercultural willingness to communicate among undergraduates in Malaysian public universities?

RQ3: What is the relationship between communication apprehension and intercultural willingness to communicate among undergraduates in Malaysian public universities?

\section{Theoretical Framework}

The framework consists of one independent variables (communication apprehension) and one dependent variable (IWTC). In this study, communication apprehension was derived mainly from the Anxiety-Uncertainty Management (AUM) theory of Gudykunst (2003). The main objective of AUM theory is to explain the relationship between anxiety, uncertainty, and mindfulness in intercultural settings in order to increase intercultural communication effectiveness. However, the present study focused only on anxiety, whereby in this study it is referred as communication apprehension. Meanwhile, as the willingness to communicate is considered as predisposition to initiate intercultural communication, IWTC is employed as the dependent variable instead of the actual intercultural communication. 


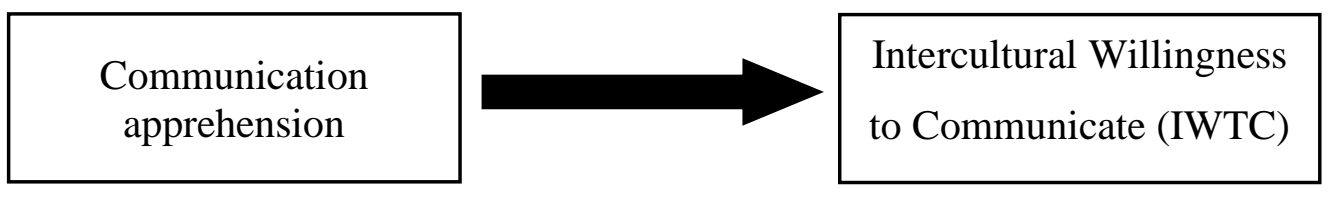

Figure 1: Research Framework

\section{Literature Review}

\section{Intercultural Willingness to Communicate (IWTC)}

Kassing (1997) defined IWTC as “one's predisposition to initiate intercultural communication encounters". Turner (1988) argued that one of the major reasons that people are not motivated to communicate with strangers is that they often do not see strangers' behaviour as predictable. Consistently, Launay and Dunbar (2015) believe that people express a greater desire to engage with strangers that they think is more similar to them, thus get attracted to maintain relationships with such strangers. Neuliep (2016) further explained that the affective component of intercultural communication is the degree to which one approaches or avoids intercultural communication, which known as one's level of motivation to interact with others from different cultures.

\section{Communication Apprehension}

Good communication is a basis of fruitful interactions, and anxiety about communicating beyond one's cultural group can affect such interactions (Cavanaugh, 2015). Communication apprehension is defined as "the fear or anxiety associated with real or anticipated communication with others" (McCroskey, 1977, p. 78). Hence, it has become an important factor that influences intercultural communication (Wang, Sun, \& Liu, 2010), especially among students which different levels of communication apprehension occurs naturally (Whitaker, 2013).

In Malaysia, most studies were focused on communication apprehension between local and international university student (Ahmad, Azimi, Salleh, Mohamad, \& Sannusi, 2017), general communication apprehension (Azrizal, 2014), and communication apprehension in second language (Lian \& Budin, 2014). Only one study by Jaganathan and Kaur (2003) which investigated the impact of communication apprehension on intercultural communication among high school Chinese and Indian students. The study revealed that $40 \%$ of Chinese students and $30 \%$ of the Indian students reported high level of anxiety. However, the sample of the study were Chinese and Indian respondents only, and the samples are not the university students. Therefore, it gives privilege to the present study to further investigate the intercultural communication apprehension among multicultural undergraduates of Malaysian public universities.

\section{Methodology}

\section{Sample Size and Procedures}

The study was carried out in five top public universities of Malaysia based on the proportionate stratified sampling. Malay, Chinese, and Indian undergraduates who are studying in these five universities are selected as the population of this study. Since the total population of these five universities is approximately 89,310 , the minimum sample size of 382 is required as suggested by Sekaran and Bougie (2016). Therefore, by expecting $80 \%$ response rate, a total of 477 
questionnaires were actually distributed to the multicultural undergraduates in these five universities, based on ethnic ratio of Malay: Chinese: Indian to 6:3:1.

The respondents were selected by using probability sampling which is systematic sampling whereby every third student who leaving the library was approached to answer the questionnaire. The process of data collection took approximately two months to complete. The researcher obtained 450 of usable responses in return, which yielded $94.33 \%$ of success rate. The number of usable responses was almost close the expected ethnic ratio of $6: 3: 1$, as shown in Table 1.

Table 1: Demographics Profiles ( $\mathrm{N}=450)$

\begin{tabular}{lcc}
\hline Ethnicity & Frequency & Percent $(\boldsymbol{\%})$ \\
\hline Malay & 272 & 60.4 \\
Chinese & 134 & 29.8 \\
Indian & 44 & 9.8 \\
Total & $\mathbf{4 5 0}$ & $\mathbf{1 0 0 . 0}$ \\
\hline
\end{tabular}

\section{The Instrument}

The questionnaire consisted a total of 23 questions in three sections. Section A consisted of four questions on the respondents' demographic information. Section B consisted of 14 questions on the communication apprehension. Section $C$ consisted of five questions on the intercultural willingness to communicate. Demographic questions in section A were designed to obtain respondents' information such as gender, ethnic, education level, and frequency of having intercultural communication in a week. The items of Section B have been adopted from Personal Report of Intercultural Communication Apprehension (PRICA) scale, developed by Neuliep and McCroskey (1997). Meanwhile, items in Section C were adapted and adopted from Kassing's (1997) IWTC scale. Items in both Section B and C were measured with a fivepoint Likert-type scale where 1 represents "Strongly Disagree", and 5 indicates "Strongly agree". Both the scales reported Cronbach's alpha value above 0.70 .

\section{Results and Analysis}

Data of PRICA and IWTC scale were analysed using the Statistical Package for the Social Science (SPSS) version 22.

RQ1: What is the level of communication apprehension among undergraduates in Malaysian public universities?

The level of communication apprehension was calculated based the formulae provided by Neuliep and McCroskey (1997). There are three steps involve in the calculation. The first step is to sum up the scores of items $1,3,5,7,9,10$, and 12. The second step is sum up the scores from items $2,4,6,8,11,13$, and 14 . And the last step is as shown below.

$$
\text { PRICA score }=(42-\text { the result from step } 1)+\text { the result from step } 2
$$

The total score can range from 14 to 70 and can be categorized into three groups as shown in Table 2. 
Table 2: Level of Communication Apprehension

\begin{tabular}{lc}
\hline PRICA scores range & Communication apprehension degree \\
between 14 and 32 & Low level \\
between 33 and 52 & Loderate level \\
between 53 and 70 & High level \\
\hline
\end{tabular}

All the three steps of calculations of PRICA score were performed via Transform >Compute variable analysis in SPSS. The mean score of PRICA is $43.55(\mathrm{SD}=2.43)$ as shown in Table 3, and the score recorded by the greatest number of respondents is 42 , which been scored by 84 $(18.7 \%)$ respondents.

Table 3: Descriptive Statistics of PRICA Score

\begin{tabular}{lccccc}
\hline & $\mathrm{N}$ & Minimum & Maximum & Mean & Std. Deviation \\
PRICA Score & 450 & 33.00 & 52.00 & 43.5543 & 2.43233 \\
Valid N (listwise) & 450 & & & & \\
\hline
\end{tabular}

Table 4: Frequency Analysis of PRICA Score

\begin{tabular}{|c|c|c|c|c|c|}
\hline & & & & Valid & Cumulative \\
\hline & & Frequency & Percent & Percent & Percent \\
\hline Valid & 33.00 & 1 & .2 & .2 & .2 \\
\hline & 34.00 & 1 & .2 & .2 & .4 \\
\hline & 35.00 & 1 & .2 & .2 & .7 \\
\hline & 36.00 & 1 & .2 & .2 & .9 \\
\hline & 37.00 & 1 & .2 & .2 & 1.1 \\
\hline & 38.00 & 4 & .9 & .9 & 2.0 \\
\hline & 39.00 & 10 & 2.2 & 2.2 & 4.2 \\
\hline & 40.00 & 1 & .2 & .2 & 4.4 \\
\hline & 40.00 & 16 & 3.6 & 3.6 & 8.0 \\
\hline & 41.00 & 33 & 7.3 & 7.3 & 15.3 \\
\hline & 42.00 & 84 & 18.7 & 18.7 & 34.0 \\
\hline & 43.00 & 72 & 16.0 & 16.0 & 50.0 \\
\hline & 44.00 & 74 & 16.4 & 16.4 & 66.4 \\
\hline & 45.00 & 54 & 12.0 & 12.0 & 78.4 \\
\hline & 46.00 & 55 & 12.2 & 12.2 & 90.7 \\
\hline & 47.00 & 23 & 5.1 & 5.1 & 95.8 \\
\hline & 47.43 & 1 & .2 & .2 & 96.0 \\
\hline & 48.00 & 9 & 2.0 & 2.0 & 98.0 \\
\hline & 49.00 & 5 & 1.1 & 1.1 & 99.1 \\
\hline & 50.00 & 1 & .2 & .2 & 99.3 \\
\hline & 51.00 & 2 & .4 & .4 & 99.8 \\
\hline & 52.00 & 1 & .2 & .2 & 100.0 \\
\hline & Total & 450 & 100.0 & 100.0 & \\
\hline
\end{tabular}


Meanwhile, the score range is between 33 and 52 as shown in Table 4. This shows that all the respondents $(100 \%)$ of this study are having a moderate level of communication apprehension. According to Logan, Steel, and Hunt (2015), a moderate level of communication apprehension is good, as it will encourage individuals to participate in intercultural communication.

RQ2: What is the level of intercultural willingness to communicate among undergraduates in Malaysian public universities?

In the present study, the IWTC score can range from 5 to 25 . Score of 12.6 and above is considered as high level of intercultural willingness to communicate, and vice-versa for IWTC score of 12.5 and below. The mean score of IWTC scale is recorded at $19.82(\mathrm{SD}=2.89)$ as shown in Table 5 , and the score obtained by most number of respondents is 20 , which been scored by $120(26.7 \%)$ respondents.

Table 5: Descriptive Statistics of IWTC Score

\begin{tabular}{lccccc}
\hline & $\mathrm{N}$ & Minimum & Maximum & Mean & Std. Deviation \\
IWTC Score & 450 & 13.00 & 25.00 & 19.8224 & 2.88757 \\
Valid N (listwise) & 450 & & & & \\
\hline
\end{tabular}

Table 6: Frequency Analysis of IWTC Score

\begin{tabular}{cccccc}
\hline & & & & Valid & Cumulative \\
Valid & & Frequency & Percent & Percent & Percent \\
13.00 & 7 & 1.6 & 1.6 & 1.6 \\
14.00 & 6 & 1.3 & 1.3 & 2.9 \\
15.00 & 34 & 7.6 & 7.6 & 10.4 \\
16.00 & 16 & 3.6 & 3.6 & 14.0 \\
17.00 & 26 & 5.8 & 5.8 & 19.8 \\
18.00 & 31 & 6.9 & 6.9 & 26.7 \\
19.00 & 62 & 13.8 & 13.8 & 40.4 \\
20.00 & 120 & 26.7 & 26.7 & 67.1 \\
20.06 & 1 & .2 & .2 & 67.3 \\
21.00 & 34 & 7.6 & 7.6 & 74.9 \\
22.00 & 34 & 7.6 & 7.6 & 82.4 \\
23.00 & 16 & 3.6 & 3.6 & 86.0 \\
24.00 & 24 & 5.3 & 5.3 & 91.3 \\
25.00 & 39 & 8.7 & 8.7 & 100.0 \\
Total & 450 & 100.0 & 100.0 & \\
\hline
\end{tabular}

Meanwhile, the score range is recorded between 13 and 25 as shown in Table 6 . This indicates that all the respondents $(100 \%)$ are highly willing to participate in intercultural communication. This finding has proved that a moderate level of communication apprehension will motivate individuals to engage in intercultural communication, as opined by Logan et al. (2015).

RQ3: What is the relationship between communication apprehension and intercultural willingness to communicate among undergraduates in Malaysian public universities?

In order to answer the third research question, Pearson correlation analysis was performed. The result in Table 7 shows that there is a significant positive correlation between the PRICA and IWTC score $(\mathrm{r}=0.259, \mathrm{p}=.000)$, which means higher the level of communication 
apprehension, it will increase the level of IWTC, and vice versa, subject to moderate level of communication apprehension.

Table 7: Pearson Correlation Result

\begin{tabular}{llrr}
\hline & & PRICA Score & IWTC Score \\
PRICA Score & Pearson Correlation & 1 & $.259^{* *}$ \\
& Sig. (2-tailed) & & .000 \\
& $\mathrm{~N}$ & 450 & 450 \\
& & & \\
IWTC Score & Pearson Correlation & $.259 * *$ & 1 \\
& Sig. (2-tailed) & .000 & \\
& $\mathrm{~N}$ & 450 & 450 \\
\hline$* *$ Correlation is significant at the 0.01 level (2-tailed).
\end{tabular}

The present study further investigated the statistically significant difference between genders, ethnic, frequency of intercultural communication, and year of study towards communication apprehension and IWTC.

Although there is no statistically significant difference found in communication apprehension between genders (Table 8), ethnics, and frequency of having intercultural communication in a week, however, statistically significant difference was evident in respondents' current year of study $(\mathrm{F}=1.948, \mathrm{df}=21, \mathrm{p}=.008)$, as shown in Table 9. This shows that students' duration of being in university influences their level of communication apprehension.

Table 8: Independent Samples Test of PRICA Score (Gender)

\begin{tabular}{|c|c|c|c|c|c|c|c|c|c|c|}
\hline & \multicolumn{2}{|c|}{\begin{tabular}{|c|} 
Levene's \\
Test for \\
Equality of \\
Variances
\end{tabular}} & \multicolumn{7}{|c|}{ t-test for Equality of Means } \\
\hline & & \multirow[t]{2}{*}{$\mathrm{F}$} & \multirow[t]{2}{*}{ Sig. } & \multirow[t]{2}{*}{$\mathrm{t}$} & \multirow[t]{2}{*}{ df } & \multirow[t]{2}{*}{$\begin{array}{l}\text { Sig. } \\
(2- \\
\text { tailed })\end{array}$} & \multirow[t]{2}{*}{$\begin{array}{c}\text { Mean } \\
\text { Difference }\end{array}$} & \multirow[t]{2}{*}{$\begin{array}{l}\text { Std. Error } \\
\text { Difference }\end{array}$} & \multicolumn{2}{|c|}{$\begin{array}{c}95 \% \\
\text { Confidence } \\
\text { Interval of the } \\
\text { Difference }\end{array}$} \\
\hline & & & & & & & & & Lower & Upper \\
\hline \multirow[b]{2}{*}{$\begin{array}{l}\text { PRICA } \\
\text { _Score }\end{array}$} & \begin{tabular}{|l} 
Equal \\
variances \\
assumed
\end{tabular} & 3.420 & .065 & -.009 & 448 & .993 & -.00249 & .27140 & -.53587 & .53088 \\
\hline & \begin{tabular}{|l} 
Equal \\
variances \\
not \\
assumed
\end{tabular} & & & -.008 & 147.578 & .993 & -.00249 & .30396 & -.60317 & .59818 \\
\hline
\end{tabular}


Table 9: ANOVA Result of PRICA Score

\begin{tabular}{llccccc}
\hline & & $\begin{array}{c}\text { Sum of } \\
\text { Squares }\end{array}$ & df & $\begin{array}{c}\text { Mean } \\
\text { Square }\end{array}$ & F & Sig. \\
Ethnic & Between Groups & 11.634 & 21 & .554 & 1.256 & .201 \\
& $\begin{array}{l}\text { Within Groups } \\
\text { Total }\end{array}$ & 188.846 & 428 & .441 & & \\
& 200.480 & 449 & & & \\
Current year of & Between Groups & 18.767 & 21 & .890 & 1.948 & .008 \\
study & Within Groups & 196.353 & 428 & .459 & & \\
& Total & 215.120 & 449 & & & \\
Frequency of & Between Groups & 17.285 & 21 & .823 & .959 & .514 \\
having & Within Groups & 367.435 & 428 & .858 & & \\
$\begin{array}{l}\text { intercultural } \\
\text { communication }\end{array}$ & Total & 384.720 & 449 & & & \\
\hline
\end{tabular}

Meanwhile for IWTC, although there is no statistically significant difference was found between genders (Table 10), ethnics, and current year of study, however, statistically significant difference was found in frequency of having intercultural communication in a week $(\mathrm{F}=1.884, \mathrm{df}=13, \mathrm{p}=.030)$, as shown in Table 11. This shows that students' frequency of having intercultural communication in a week did influence their IWTC.

Table 10: Independent Samples Test of IWTC Score (Gender)

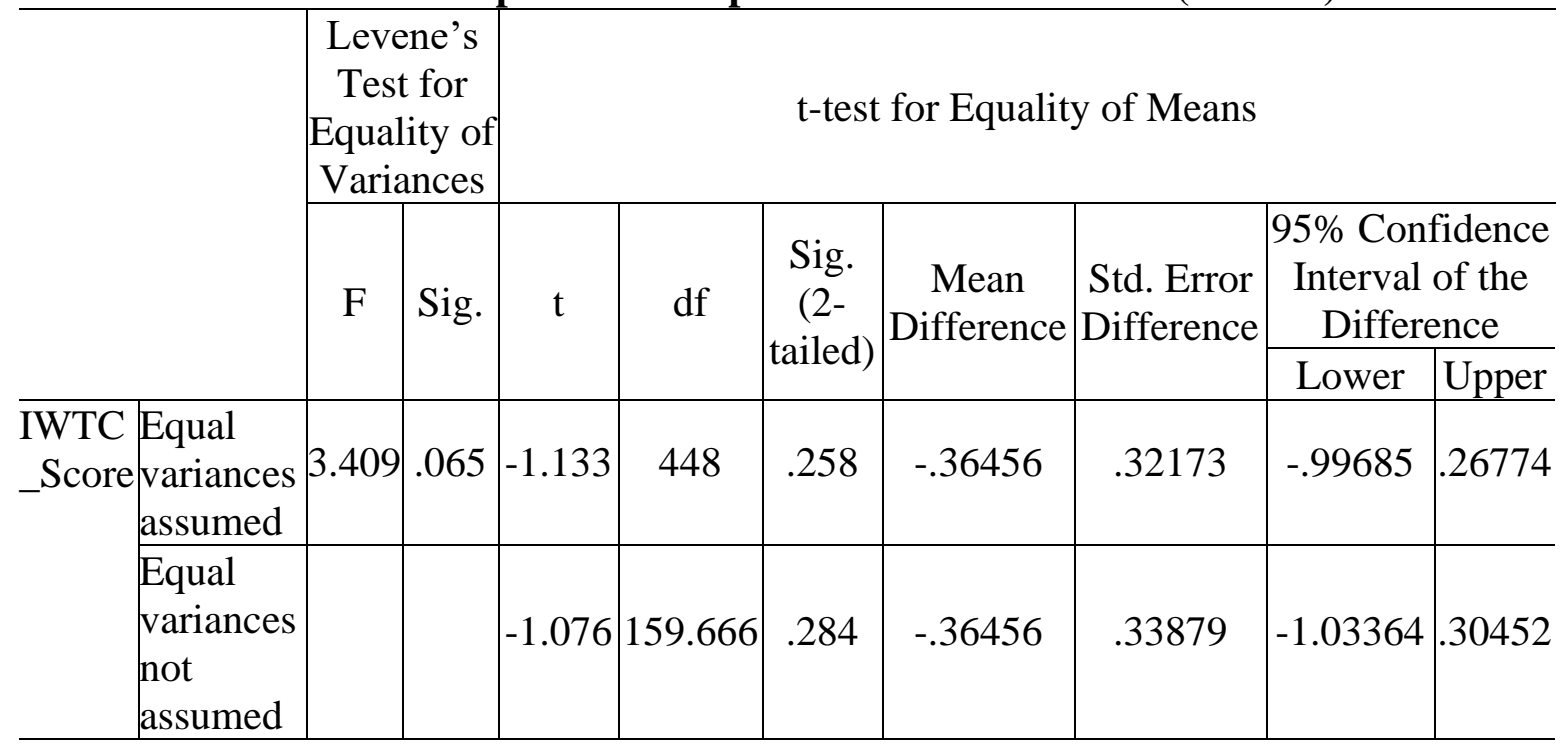


Table 11: ANOVA Result of IWTC Score

\begin{tabular}{|c|c|c|c|c|c|c|}
\hline & & $\begin{array}{l}\text { Sum of } \\
\text { Squares }\end{array}$ & df & $\begin{array}{l}\text { Mean } \\
\text { Square }\end{array}$ & $\mathrm{F}$ & Sig. \\
\hline \multirow[t]{3}{*}{ Ethnic } & Between Groups & 7.299 & 13 & .561 & \multirow[t]{3}{*}{1.267} & \multirow[t]{3}{*}{.230} \\
\hline & Within Groups & 193.181 & 436 & .443 & & \\
\hline & Total & 200.480 & 449 & & & \\
\hline \multirow{3}{*}{$\begin{array}{l}\text { Current year of } \\
\text { study }\end{array}$} & Between Groups & 9.971 & 13 & .767 & \multirow[t]{3}{*}{1.630} & \multirow[t]{3}{*}{.074} \\
\hline & Within Groups & 205.149 & 436 & .471 & & \\
\hline & Total & 215.120 & 449 & & & \\
\hline \multirow{3}{*}{$\begin{array}{l}\text { Frequency of } \\
\text { having } \\
\text { intercultural } \\
\text { communication }\end{array}$} & \multirow{3}{*}{$\begin{array}{l}\text { Between Groups } \\
\text { Within Groups } \\
\text { Total }\end{array}$} & 20.457 & 13 & 1.574 & \multirow[t]{3}{*}{1.884} & \multirow[t]{3}{*}{.030} \\
\hline & & 364.263 & 436 & .835 & & \\
\hline & & 384.720 & 449 & & & \\
\hline
\end{tabular}

\section{Discussion}

The aim of the study is to investigate the relationship between communication apprehension and IWTC. The results of this research had yielded some significant insights. In regard to communication apprehension, this present study revealed that all 450 respondents (100\%) are having moderate level of communication apprehension and were found having high willingness to communicate in intercultural settings. Although no past studies have reported similar result, but some past studies had observed that when communication apprehension is at moderate level, one will be more willing to participate in intercultural communication (Gudykunst, 2003; Neuliep, 2016). This has been proved in this study whereby all the respondents who had reported moderate level of communication apprehension are correlated with their high IWTC.

The findings indicate that the undergraduates in Malaysian public universities are able to maintain their communication apprehension at the minimum and maximum threshold level, which contradict the findings of Pragash et al. (2018). This is due to the different environments between private and public universities in Malaysia, whereby the ethnic composition in public universities are more diverse than the private universities. Therefore, as professed by Allport's (1954) Contact Theory, such diverse cultural environment provides a comprehensive and favourable platform to the multicultural undergraduates to mingle around and further strengthen their intercultural bonding. Hence, Malaysian public universities should continue with the existing university practices to uphold the harmonies intercultural relationship among multicultural undergraduates.

\section{Recommendation}

The present study found that undergraduates in Malaysian public universities are highly willing to communicate interculturally. However, we cannot assume that this high level of willingness reflects the actions taken by them in the actual intercultural communication or interaction. Hence, it is important to further investigate the impact of IWTC on the actual intercultural interaction among multicultural undergraduates in Malaysian public universities. Furthermore, significant difference was found between students' current year of study and communication apprehension, and also between students' frequency of intercultural communication and IWTC. Therefore, future studies should consider employing qualitative approaches to further investigate the impact of year of study and frequency of intercultural communication on both communication apprehension and IWTC. 


\section{Acknowledgement}

This research was supported by Universiti Tunku Abdul Rahman Research Fund 2018 - Cycle 2 (IPSR/RMC/UTARRF/2018-C2/P02) from Universiti Tunku Abdul Rahman, Kampar Campus.

\section{References}

Ahmad, A. L., Azimi, H., Salleh, S., Mohamad, E. M. W., \& Sannusi, S. N. (2017). The intercultural adaptation experience of afghan students in Malaysia. In SHS Web of Conferences, 33, 1-6. EDP Sciences.

Allport, G. W. (1954). The Nature of Prejudice. Reading, MA: Addison-Wesley.

Arnett, R. C. (1986). Communication and Community: Implications of Martin Buber's Dialogue. Carbondale: Southern Illinois U Press.

Azrizal, M. (2014). Communication Apprehension among First-year Engineering Degree Students of Universiti Malaysia Perlis. Center for International Languages, Universiti Malaysia Perlis, Malaysia, 1-3.

Behbahani, M. (2013). Intercultural Communication, a key to integration (Master's thesis). University of Gothenburg, Sweden.

Cavanaugh, S. A. (2015). Intercultural contact, communication apprehension, and social perspective taking. Working Papers in Education, 1(1), 1-25.

Croucher, S. M. (2017). Global perspectives on intercultural communication. New York: Routledge Taylor \& Francis.

Gudykunst, W. B. (2003). Understanding Must Precede Criticism: A Response to Yoshitake's Critique of Anxiety/Uncertainty Management Theory. Intercultural Communication Studies, 12(1), 25-40.

Jaganathan, T., \& Kaur, M. (2003). The Influence of Culture on the Communicative Style of Students in a Malaysian Secondary School. Journal of Language Teaching, Linguistics and Literature, 8, 63-76.

Kassing, J. W. (1997). Development of the intercultural willingness to communicate scale. Communication Research Reports, 14, 399-407.

Launay, J., \& Dunbar, R. I. (2015). Playing with strangers: which shared traits attract us most to new people? PloS one, 10(6), e0129688.

Lian, L. H., \& Budin, M. (2014). Investigating the relationship between English language anxiety and the achievement of school based oral English test among Malaysian Form Four students. International Journal of Learning, Teaching and Educational Research, 2(1), 67-79.

Logan, S., Steel, Z., \& Hunt, C. (2015). Investigating the effect of anxiety, uncertainty and ethnocentrism on willingness to interact in an intercultural communication. Journal of Cross-Cultural Psychology, 46(1), 39-52.

McCroskey, J. C. (1977). Oral communication apprehension: A summary of recent theory and research. Human Communication Research, 4, 78-96.

Neuliep, J. W. (2016). Intercultural Communication: A Contextual Approach. Thousand Oaks: Sage Publications.

Neuliep, J. W., \& McCroskey, J. C. (1997). The development of intercultural and interethnic communication apprehension scales. Communication Research Reports, 14, 385-398.

Pragash, M. Sultana, M. A., \& Khor, K. K. (2018). Ethnocentrism and Intercultural Willingness to Communicate: A Study of Malaysian Private University. International Journal of Law, Government and Communication, 3(12), 16-23. 
Sekaran, U., \& Bougie, R. (2016). Research methods for business: A skill building approach. John Wiley \& Sons.

Seyitoglu, F., Guven, A., \& Kocabulut, O. (2015). Effects of intercultural communication apprehension on satisfaction of foreign students. In First European Academic Research Conference on Global Business, Economics, Finance and Social Sciences (EARL 5Italy Conference). Milan, Italy.

Turner, J. H. (1988). A theory of social interaction. CA, California: Stanford University Press.

Wang, S., Sun, X., \& Liu, C. (2010). Intercultural analysis of communication anxieties encountered by international students in the United States. Intercultural Communication Studies, 14(2), 217-234.

Whitaker, M. S. (2013). Anxiety/uncertainty management and its relationship to community as an anxiety management mechanism: A mixed methods, across case study of online graduate students. (Doctoral dissertation). University of Alabama, Alabama. 